\title{
Research on Safety Risk Assessment Method of Amphibious Equipment at Maritime Training
}

\author{
Jianhua Luo, Naibo Zheng, ${ }^{2, *}$, Da Xu ${ }^{3}$ and Qingyang Guo ${ }^{4}$ \\ Department of Arms Engineering, Academy of Armored Force Engineering, Beijing 100072, China \\ ${ }^{*}$ Corresponding author
}

\begin{abstract}
This paper aims amphibious equipment maritime training safety risk assessment, introduces the definition, purpose and basis of amphibious equipment maritime training safety risk assessment, the evaluation process and evaluation method are studied, puts forward the comprehensive evaluation method based on AHP and fuzzy mathematics, provides a theoretical basis for the better development of amphibious equipment maritime training safety risk assessment.
\end{abstract}

Keywords-amphibious equipment; maritime training; safety risk assessment

\section{INTRODUCTION}

Amphibious equipment with superior water and land properties, strong firepower and protection ability, good ability to adapt to the land and sea, as the main equipment has been fitted out of our army. Amphibious equipment on the sea training environment than the land have a greater difference, in addition to the heavy combat mission, the steps are complex, special environment, the risk coefficient of the larger, the members of the physical and psychological quality requirements. At present, the security problem of amphibious equipment maritime training is more prominent, there are more security risks, and affect greatly the training enthusiasm and hinder the formation of combat, so the research has important significance to improve the level of training for amphibious equipment maritime training security risk assessment method.

\section{OVERVIEW OF THE AMPHIBIOUS EQUIPMENT MARITIME TRAINING SAFETY RISK ASSESSMENT}

\section{A. Definition of Amphibious Equipment Maritime Training Safety Risk Assessment}

Security risk assessment[1] refers to the comprehensive use of safety system engineering to measure and predict the risk through the identification, the risk of system existence or unsafe factors of qualitative and quantitative analysis, confirm the system risk possibility and severity.

The safety risk assessment of the marine training for amphibious equipment is the assessment and measurement of the risk size of the amphibious equipment. Maritime training amphibious equipment safety assessment is to realize the sea training amphibious equipment safety, according to the principle and method of safety system engineering, to find out the potential risk of marine amphibious equipment training, reasons and the transformation conditions, potentially dangerous consequences of safety risk evaluation, the size of the amphibious equipment maritime training to make qualitative and quantitative put forward the corresponding measures and suggestions, to eliminate potential hazards, ensure the safety of maritime training amphibious equipment.

\section{B. Objective to Evaluate the Safety Risk Assessment of Amphibious Equipment at Sea Training.}

The purpose of the safety risk assessment of marine training for amphibious equipment is to reduce accidents and prevent accidents, so that the amphibious equipment can be in a state of "zero accident" during a certain period of time[2]. In particular through the security risk assessment of marine amphibious equipment training, and find out the risk factors existing in the training process, the potential risk to determine the feasibility of measures to reduce the accident rate of training, training to ensure safety of. Based on this, we can say that the development of marine training amphibious equipment safety risk assessment is to determine the equipment training safety risk control and disposal method; reducing training accident frequency; reduce the extent and severity of accident loss.

\section{The Basis for the Safety Risk Assessment of Amphibious Equipment at Sea Training}

The basis of carrying out the safety risk assessment of amphibious equipment at sea training mainly has the following several aspects:

- The basic information of the marine training of amphibious equipment, such as: equipment operating procedures, training subjects types, training conditions, training safety risk management plan, etc.

- Current safety risk identification results of amphibious equipment.

- The accuracy and reliability of the data collected by the safety risk.

- $\quad$ The security risk probability and impact. 


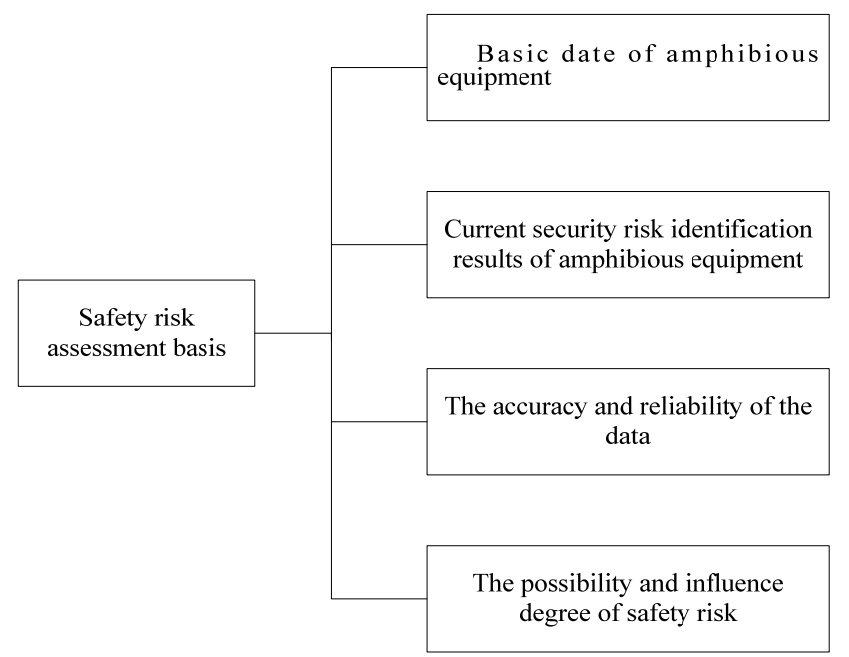

FIGURE I. SAFETY RISK ASSESSMENT BASIS

\section{SAFETy Risk AsSESSMENT PROCESS FOR AMPHIBIOUS EQUIPMENT AT SEA TRAINING}

The safety risk assessment is a real time and repeated expansion in the course of the amphibious equipment training at sea. Analysis of maritime training amphibious equipment safety risk assessment process, is to analyze the relevant constraint mechanism will be amphibious equipment maritime training this input into security risk assessment of dynamic process of the output, finally realizes the analysis and description of the process of marine amphibious equipment safety risk assessment training. From domestic and international experience shows that the establishment of maritime training amphibious equipment safety risk assessment system mainly has six basic steps: risk identification, risk factors, risk factors of qualitative and quantitative check evaluation, control and disposal of dangerous factors, comprehensive evaluation, report compilation.

\section{A. Definition of Safety Risk Assessment Process for Amphibious Equipment at Sea Training}

- Input of security risk assessment process. Maritime training amphibious equipment safety risk assessment process inputs: amphibious equipment maritime training environment, amphibious equipment operation, amphibious equipment maritime training task requirements, training courses, training status, training type safety risk management plan, developed by experts amphibious equipment maritime training safety risk assessment level and standard.

- The output of security risk assessment process. The output of the process of safety risk assessment for amphibious equipment is mainly: the safety risk status of the equipment at sea, the safety risk ranking list, the safety risk response control strategy.

\section{B. Work on the Process of Safety Risk Assessment}

- Analysis on the environmental factors of the safety risk assessment of the amphibious equipment at sea training.
- It is clear that the security risks of amphibious equipment in the sea can be accepted standard. The acceptable standard of safety risk refers to the acceptable level of the consequences of each risk arising in the course of sea training.

- Identification of key safety risk factors for marine training of amphibious equipment. It is the basis of safety risk assessment to find out the key factors of the safety risk of the amphibious equipment by using the reasonable safety analysis technique.

- The determination of amphibious equipment maritime training overall safety risk level.

- $\quad$ The proposed security risk measures and suggestions.

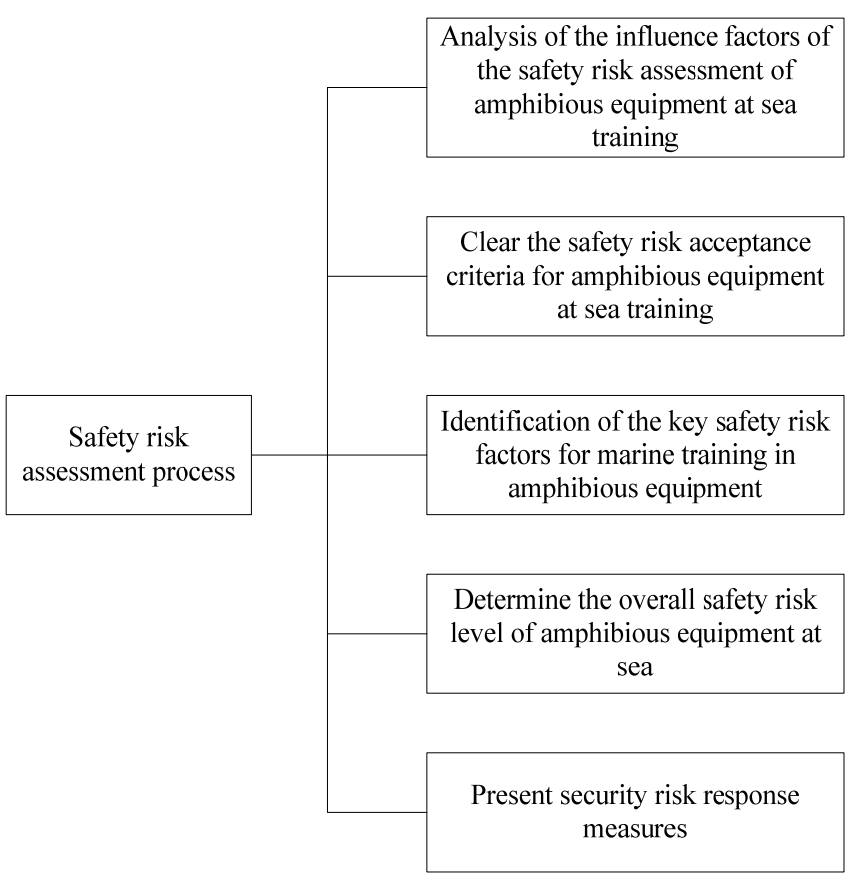

FIGURE II. SAFETY RISK ASSESSMENT PROCESS

\section{RESEARCH ON SAFETy Risk AsSESSMENT METHOD}

Safety risk assessment is a tool for qualitative and quantitative safety assessment. Safety risk assessment content and indicators are different, the use of security risk assessment methods are also different. There are many methods of safety risk assessment, which can be divided into: qualitative assessment, quantitative assessment, qualitative and quantitative combination of comprehensive assessment. When the safety risk assessment is carried out, the appropriate safety risk assessment method should be selected according to the safety evaluation object and the goal of safety assessment.

\section{A. Qualitative Assessment of Security Risk}

Qualitative assessment[3] is mainly based on experience and intuitive ability to assess the status of the system to make the assessment, the assessment results are some of the qualitative indicators. Commonly used qualitative assessment methods are safety inspection table, Delphy method, fault type 
and impact analysis, hazard and operability analysis method. Qualitative assessment pays attention to the consequence caused by the occurrence of security incidents, ignoring the probability of the occurrence of security incidents, the conclusion has a strong subjectivity, the assessment of the quality of their own requirements.

\section{B. Quantitative Risk Assessment}

Quantitative assessment[4] is to quantify the assessment of the elements according to a certain standard, and then use a certain mathematical methods or models for quantitative analysis of these data, so as to draw the conclusion. Quantitative assessment methods are commonly used clustering analysis method, regression model and decision tree. The quantitative assessment results from the evaluation of staff can be very intuitive, concise see the relationship between data acquisition, data objectively and scientifically, but quantitatively evaluate assessment personnel with sufficient behind the mathematical foundation, and the quantitative assessment to quantify some complex data, but will make it more fuzzy, so the conclusion is not deep enough.

\section{Comprehensive Evaluation of Safety Risk}

Qualitative assessment and quantitative assessment methods have their advantages and disadvantages, but they are complementary to each other. Qualitative assessment method requires less resources, but the results are not accurate, with strong subjectivity, it is based on the assessment of knowledge, experience and evaluation method. Quantitative assessment methods using mathematical models and mathematical methods, the results are more accurate, strong logic, but the cost of more resources, the cost is also higher. Qualitative is the quantitative basis, quantitative qualitative is the specific, only the perfect combination of the two together, in order to achieve a better assessment of the results. At present, based on the qualitative and quantitative assessment of the comprehensive security risk assessment methods are mainly based on the analytic hierarchy process and its derivation method.

Analytical Hierarchy Process (AHP)[5,6] in mid 1970s by the United States operations scientist T.L.Saaty formally proposed a combination of qualitative and quantitative, multi program systematic and hierarchical analysis method. AHP is systematic, simple and practical, need quantitative data less information and other advantages, but only use AHP quantitative data and qualitative components are less is more, the result does not have a strong persuasive index; excessive data statistics, and it is difficult to determine the weight disadvantage.

The comprehensive evaluation method based on the fuzzy theory[7] is a very effective multi factor evaluation method for the comprehensive evaluation of the things which are affected by many factors. Due to the changing conditions of risk events occur, maritime training amphibious equipment is uncertain risk; in addition, because of the risk events are caused by one or more risk factors, risk probability and impact degree only for human cognitive, so can only rely on expert assessment of the approximate quantification of risk but experts are fuzzy evaluation process.
Traditional AHP method considers only the most likely estimate of the experts in the comparison of the value of the risk factor 22, but can not take into account the fuzziness and uncertainty of the expert judgment. So considering the expert judgment of fuzzy and uncertainty on the basis of the combination of AHP method and fuzzy ranking method based on possibility degree judgment matrix ranking of risk factors, to determine the weight of risk factors.

\section{Selection of Safety Risk Assessment Method}

Amphibious equipment at sea training to carry out security risk assessment to take into account the personnel, environment, equipment, organizational planning and other factors. These factors include personnel's ability, psychological quality and other factors; environmental factors including environmental factors, temperature and humidity inside the amphibious equipment noise, vibration, ventilation, harmful gas concentration, temperature and humidity, wind speed, weather, sea conditions and other environmental factors also include the exterior of the vehicle; equipment factors include the equipment itself of each system, parts of the situation. Taking into account the marine training of amphibious equipment is a large human - machine - ring system, so we can use the analytic hierarchy process to carry on the systematic, hierarchical qualitative and quantitative safety risk assessment. Due to environmental factors, temperature and humidity, weather, sea conditions and other factors and psychological quality, state is constantly changing, maritime training risk of amphibious equipment with uncertainty, and expert scoring method gives the fuzziness and subjectivity are also in the process of weight factors, so the amphibious equipment security risk assessment process can be used to start the safety risk assessment of marine amphibious equipment training fuzzy analytic hierarchy process.

\section{CONCLUDING REMARKS}

Based on the characteristics of the amphibious armoured vehicle maritime training, analysis of the security risk assessment of the meaning, basis and purpose, and to analyze the input and output process are systematically analyzed and summarized the amphibious armored assault vehicle maritime training safety risk, at the end of this paper to carry out maritime training amphibious equipment safety risk assessment methods the research for the next step to lay the theoretical foundation for establishing marine amphibious equipment training safety risk assessment model is scientific and reasonable.

\section{REFERENCES}

[1] He Zheng-you, Feng Ding. Research on Security Risk Assessment for Traction Power Supply System of High-speed Railway [J]. Journal of Southwest Jiaotong University, 2016,51 (3): 418-429.

[2] Wu Ming, Zhu Quan-hua, Yang Hong-qing. Safety evaluation index system study of large ship lock construction [J]. Journal of Waterway and Harbor, 2015,36 (1): 79-83.

[3] Chen Yan-yun. Research and Application of Bus Voltage Stability Analysis Method for Power Plants [J]. Electrical Engineering, 2015, (11) 48-52. 
[4] DAI Shun-an, Wang Ye, CAI Jing. Research on Quantitative Risk Assessment Method for Hidden Failure of Civil Aircraft [J]. Journal of Sichuan Ordnance, 2016,37 (6): 162-165.

[5] CHEN Jian-ping; XU Jie; GONG You; HUANG Peng-ju; XU Yan-min. Research on the analytic hierarchy process model of ship optimization based on variable value method [J]. Ship Science and Technology, 2016, (9): 69-73 78

[6] Li Wei-feng; Wang Qing-fu. Power grid security situation analysis based on AHP and neural network [J]. Modern Electronic Technique, 2016,39 (15): 145-148.

[7] ZHANG Yong. Smart Grid Operation Risk Assessment System Based on Fuzzy Theory [J]. Power \& Energy, 2015,36(3):283-286 